
August 1934

\title{
HEATS OF COMBUSTION AND OF FORMATION OF THE NORMAL ALIPHATIC ALCOHOLS IN THE GASEOUS AND LIQUID STATES, AND THE ENERGIES OF THEIR ATOMIC LINKAGES
}

\author{
By Frederick D. Rossini
}

\section{ABSTRACT}

The existing data on the heats of combustion and of vaporization of the normal aliphatic alcohols are correlated with the value recently proposed by the writer for the increase in the heat of combustion per added $\mathrm{CH}_{2}$ group. Selected "best" values are given for the heats of vaporization at 25 centigrade; for the heats of combustion of the gas and the liquid at 25 centigrade; for the heats of formation from solid carbon and gaseous hydrogen and oxygen at 25 centigrade and at zero Kelvin; and for the heat of the reaction $\mathrm{C}_{n} \mathrm{H}_{2 n+2}$ (gas) $+1 / 2 \mathrm{O}_{2}$ (gas) $=$ $\mathrm{C}_{n} \mathrm{H}_{2 n+1} \mathrm{OH}$ (gas) at 25 centigrade and at zero Kelvin.

The energy of dissociation, at the absolute zero, of the normal aliphatic alcohol, $\mathrm{C}_{n} \mathrm{H}_{2 n+1} \mathrm{OH}$, into its constituent atoms is found to be a linear function of the number of carbon atoms above, but not below, $n$ equal to about 6 . The deviations from linearity are in the direction of lesser stability of the molecule and have the following values, in kilocalories per mole: methanol, $-3.78 \pm 0.10$; ethanol, $-1.18 \pm 0.20$; normal propanol, $-0.60 \pm 0.40$; normal butanol, $-0.30 \pm 0.55$; normal pentanol, $-0.15 \pm 0.70$. The deviations can be explained by distinguishing different kinds of $\mathrm{C}-\mathrm{H}, \mathrm{C}-\mathrm{C}$, and $\mathrm{C}-\mathrm{O}$ linkages in these molecules.

I. Introduction. .

II. Units, molecular weights, etc

III. Heats of vaporization

IV. Existing data on heats of combustion

V. Selected values for the heats of combustion of the alcohols in the liquid state

VI. Selected values for the heats of combustion of the alcohols in the gaseous state

VII. Change in heat content, at 25 centigrade and at zero Kelvin, for the reaction of adding $1 / 2 \mathrm{O}_{2}$ to a normal paraffin hydrocarbon to form the corresponding normal aliphatic alcohol

VIII. Heats of formation of the normal aliphatic alcohols from solid carbon and gaseous hydrogen and oxygen.

IX. Energy of dissociation of normal $\mathrm{C}_{n} \mathrm{H}_{2 n+1} \mathrm{OH}$ into gaseous atoms, and the energies of the atomic linkages...

X. References 


\section{INTRODUCTION}

In a previous paper by the writer $(1)^{1}$ on the heats of combustion of the gaseous normal paraffin hydrocarbons, the following generalization was made: In any organic molecule containing: a normal alkyl group of more than 5 carbon atoms, the addition of a $\mathrm{CH}_{2}$ group to the normal alkyl radical to form the next higher normal alkyl group results in an increase in the heat of combustion of the organic molecule in the gaseous state, at a temperature of 25 centigrade and a constant total pressure of 1 atmosphere, of $157.00 \pm 0.08$ $\mathrm{k}-\mathrm{cal}_{15}$ per mole.

In this paper, the above rule, together with the values obtained in this laboratory for the heats of combustion of methanol and ethanol, is utilized to correlate all the published data on the heats of combustion and of vaporization of the normal aliphatic alcohols, to deduce "best" values for the heats of combustion and of formation of these molecules in the liquid and gaseous states, to compute values for the energies of dissociation of these molecules into their constituent atoms, and to deduce certain relationships concerning the energies of the atomic linkages.

\section{UNITS, MOLECULAR WEIGHTS, ETC.}

In every case where the distinction is at all significant, the values of energy given in this paper are based upon the international joule as derived from standards maintained at this bureau. As in the previous papers, the following conversion factor ${ }^{2}$ is used for reporting the results in calories:

$$
1 \text { international joule }=1.00040 / 4.1850 \mathrm{~g}-\mathrm{cal}_{15} .
$$

The establishment of the uncertainties attached to the various values presented in this paper follows the procedure of the previous papers from this laboratory.

In utilizing the data of those experiments of other investigators where the amount of reaction was determined from the mass of liquid alcohol burned, the value of the heat of combustion per mole was obtained by multiplying the heat of combustion per true gram mass by the molecular weight of the alcohol, computed from the following atomic weights: oxygen, 16.0000 ; hydrogen, 1.0078 ; carbon 12.007 . The 1934 report of the International Committee on Atomic Weights (3) gives the atomic weight of carbon as 12.00 , but there is now little doubt that the true value is greater than this by about 0.05 to 0.08 percent. $^{3}$ In this paper, it is necessary to use the value that most nearly represents the atomic weight of carbon, otherwise one is led into the peculiar position of dealing with significantly different sized moles of the same substance. For example, in determining the heat of combustion of hexanol per mole, the amount of reaction in the calorimetric combustion experiments may be determined in three ways: first, from the mass of hexanol divided by its molecular weight; second, from the mass of carbon dioxode formed in the combustion divided by six times the molecular weight of carbon dioxide;

1 Figures in parentheses here and throughout the text refer to the references at the end of this paper, p. 201 .

See p. 736 of reference (2).

See p. 27 of reference (1). 
and, third, from the mass of water formed in the reaction divided by seven times the molecular weight of water. If the true atomic weight of carbon is 12.007 , then the use of the value 12.00 introduces in the foregoing procedures the following respective errors: first, 0.041 percent; second, 0.016 percent; third, 0.000 percent. In order to obtain the greatest possible accuracy and consistency from the existing data, the value 12.007 is used in this paper for the atomic weight of carbon.

Any accurate measurement of the heat of combustion of an organic compound requires the accurate determination of the amount of reaction per mole of substance burned, from the mass of water or the mass of carbon dioxide formed in the reaction; and if the combustion occurs in a bomb under pressure, then the conditions of the bomb

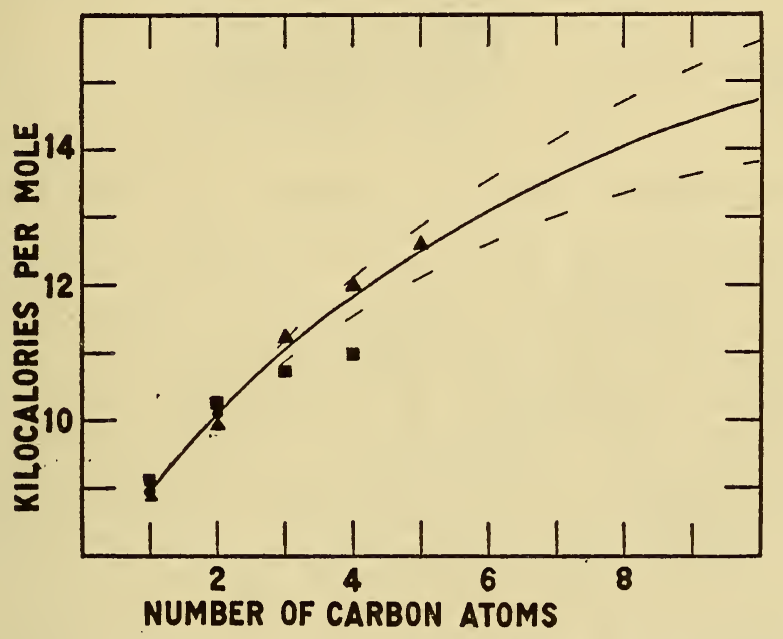

Figure 1.-Plot of the various data on the heats of vaporization of the normal aliphatic alcohols.

The scale of ordinates gives the heat of vaporization at a temperature of $25 \mathrm{C}$ and at saturation pressure, in $\mathrm{k}$-cal ${ }_{15}$ per mole. The scale of abscissas gives the number of carbon atoms in the normal aliphatic alcohol, $\mathrm{C}_{n} \mathrm{H}_{2 n+1} \mathrm{OH}$. The dashed lines indicate the estimated uncertainty.

The various data are indicated as follows: Fiock, Ginnings, and Holton (7); 1 , Bartoszewicz (6); $\Delta$, International Critical Tables (5).

process should be accurately specified in order that the Washburn (4) conversion to 1 atmosphere may be made without error.

\section{HEATS OF VAPORIZATION}

The existing data on the heats of vaporization of the normal aliphatic alcohols are those given in the International Critical Tables (5) together with the recently reported measurements of Bartoszewicz (6) and of Fiock, Ginnings, and Holton (7).

The various data, corrected to a temperature of $25 \mathrm{C}$ where necessary, are plotted in figure 1 . Unplotted values deduced from vapor pressure data have been used to extrapolate the curve to normal decyl alcohol and to estimate the limits of uncertainty. From these and other considerations brought out later in this paper, the writer believes that there must be an error in the values recently reported by 
Bartoszewicz (6) for the heats of vaporization of normal propyl and normal butyl alcohols.

From the curve in figure 1 , the values given in table 1 have been selected as the "best" values for the heats of vaporization of the normal aliphatic alcohols at saturation pressure and a temperature of $25 \mathrm{C}$.

TABLE 1.-Selected "best" values for the heats of vaporization of the normal aliphatic alcohols at saturation pressure and a temperature of. $25 \mathrm{C}$

\begin{tabular}{|c|c|c|c|}
\hline Normal $\mathrm{C}_{n} \mathrm{H}_{2 n+1} \mathrm{OH}$ & $\begin{array}{l}\text { Heat of vapor- } \\
\text { ization at } 25 \\
\text { centigrade }\end{array}$ & Normal $\mathrm{C}_{n} \mathrm{H}_{2 n+1} \mathrm{OH}$ & $\begin{array}{l}\text { Heat of vapor } \\
\text { ization at } 25 \\
\text { centigrade }\end{array}$ \\
\hline $\begin{array}{l}\text { Methanol } \\
\text { Ethanol } \\
\text { Normal propanol } \\
\text { Normal butanol } \\
\text { Normal pentanol-... }\end{array}$ & $\begin{array}{r}\text { k-cal per mole } \\
8.94 \pm 0.01 \\
10.12 \pm 0.02 \\
11.05 \pm 0.15 \\
11.80 \pm 0.25 \\
12.45 \pm 0.35\end{array}$ & $\begin{array}{l}\text { Normal hexanol } \\
\text { Normal heptanol } \\
\text { Normal octanol } \\
\text { Normal nonanol } \\
\text { Normal decanol. }\end{array}$ & $\begin{array}{r}k \text {-cal per mole } \\
13.05 \pm 0.45 \\
13.55 \pm 0.55 \\
14.00 \pm 0.70 \\
14.40 \pm 0.85 \\
14.70 \pm 1.00\end{array}$ \\
\hline
\end{tabular}

\section{EXISTING DATA ON HEATS OF COMBUSTION}

The existing data on the heats of combustion of methyl and ethyl alcohols are discussed in a previous paper by the writer (8). The experimental values obtained 3 years ago in this laboratory for the heats of combustion of methyl and ethyl alcohols in the gaseous state at a constant total pressure of 1 atmosphere are: $\mathrm{CH}_{3} \mathrm{OH}$ (gas), at 25 centigrade, 763.68 international kilojoules per mole (measured as $44.000 \mathrm{~g}$ of $\mathrm{CO}_{2}$ ): $\mathrm{C}_{2} \mathrm{H}_{5} \mathrm{OH}$ (gas), at 32.50 centigrade, $1,407.50$ international kilojoules per mole (measured as $88.000 \mathrm{~g}$ of $\mathrm{CO}_{2}$ ). With the value 12.007 for the atomic weight of carbon, there are obtained 44.007 and $88.014 \mathrm{~g}$ for the masses of $\mathrm{CO}_{2}$ produced by 1 mole of $\mathrm{CH}_{3} \mathrm{OH}$ and of $\mathrm{C}_{2} \mathrm{H}_{5} \mathrm{OH}$, respectively. This necessitates an increase of 0.016 percent in the values given above for the heats of combustion per mole, which become: $\mathrm{CH}_{3} \mathrm{OH}$ (gas), at 25 centigrade, 763.80; $\mathrm{C}_{2} \mathrm{H}_{5} \mathrm{OH}$ (gas), at 32.50 centigrade, $1,407.72$, international kilojoules per mole at a constant total pressure of 1 atmosphere. Conversion to the standard temperature and to the liquid state yields the following values for the heats of combustion at 25 centigrade and a constant total pressure of 1 atmosphere:

\begin{tabular}{|c|c|c|}
\hline Substance & $\begin{array}{l}\text { International } \\
\text { kilojoules per } \\
\text { mole }\end{array}$ & $\begin{array}{c}\mathrm{k}-\mathrm{cal}_{15} \text { per } \\
\text { mole }\end{array}$ \\
\hline $\begin{array}{l}\mathrm{CH}_{3} \mathrm{OH} \text { (gas) } \\
\mathrm{C}_{2} \mathrm{H}_{5} \mathrm{OH} \text { (gas) } \\
\mathrm{CH}_{3} \mathrm{OH} \text { (liquid) } \\
\mathrm{C}_{2} \mathrm{H}_{5} \mathrm{OH} \text { (liquid) }\end{array}$ & $\begin{array}{r}763.80 \pm 0.20 \\
1,408.83 \pm 0.40 \\
726.37 \pm 0.20 \\
1,366.51 \pm 0.40\end{array}$ & $\begin{array}{l}182.58 \pm 0.05 \\
336.78 \pm 0.10 \\
173.64 \pm 0.05 \\
326.66 \pm 0.10\end{array}$ \\
\hline
\end{tabular}

The following list includes all the investigations which have been published on the heats of combustion of the normal aliphatic alcohols above ethanol: Louguinine (9), propanol; Zubow (10), propanol, butanol, heptanol; Richards and Davis (11), propanol, butanol; Verkade and Coops (12), butanol, pentanol, hexanol, heptanol, octanol, nonanol, decanol. 
Because of the uncertainty of the conversion of his unit of energy, the data of Louguinine (9) on normal propanol are now only of historical interest.

The data of Zubow (10) were recalculated by Swietoslawski (13). The writer has made the Washburn conversion to 1 atmosphere and converted the values given by Swietoslawski to a temperature of $25 \mathrm{C}$, obtaining the following values for the heats of combustion of the liquids at a temperature of $25 \mathrm{C}$ and a constant pressure of 1 atmosphere: normal propanol, $480.6 \pm 1.2$; normal butanol, $638.6 \pm 1.6$; normal heptanol, $1,105.0 \pm 2.8, \mathrm{k}-\mathrm{cal}_{15}$ per mole.

The data of Richards and Davis (11), who did not calibrate their calorimeter electrically, have been converted into the present unit of energy by the use of the factor which makes their value for ethanol identical with that obtained by the writer 3 years ago (8). Following this procedure, the writer obtains from their data the following values for the heats of combustion of the liquid at a temperature of $25 \mathrm{C}$ and at a constant pressure of 1 atmosphere: normal propanol, $482.1 \pm$ 0.6 ; normal butanol, $637.7 \pm 0.8, \mathrm{k}-\mathrm{cal}_{15}$ per mole.

Verkade and Coops (12) made a careful study of the heats of combustion of the liquid normal aliphatic alcohols from butanol to decanol. These investigators calibrated their calorimeter with benzoic acid, operating at a temperature of $19.5 \mathrm{C}$ and using in their bomb an initial oxygen pressure of 35 atmospheres. For the heat of combustion of benzoic acid in the bomb calorimeter under these conditions, Verkade and Coops used the value 6,324.0 $\mathrm{cal}_{15}$ per gram weighed in air, which is equivalent to $6,318.9 \mathrm{cal}_{15}$ per true gram mass. From recent experiments at this bureau, Jessup (14) has found the heat of combustion of benzoic acid in a bomb calorimeter at a temperature of $25 \mathrm{C}$ to be 26,419 international joules per true gram mass, under the standard conditions (of the bomb process) proposed by Washburn (4). For the conditions of the experiments of Verkade and Coops, Jessup's value becomes 26,427 international joules, or, using the factor $1.00040 / 4.1850,6,317.2$ cal $_{15}$ per true gram mass of benzoic acid. The Washburn correction to 1 atmosphere which must be applied to these data of Verkade and Coops is computed to be -0.035 percent. On conversion to a temperature of $25 \mathrm{C}$, the data of Verkade and Coops yield the following values for the heat of the reaction,

$$
\begin{aligned}
\mathrm{C}_{n} \mathrm{H}_{2 n+1} \mathrm{OH} \text { (liquid) }+\frac{3 n}{2} & \mathrm{O}_{2} \text { (gas) } \\
& =n \mathrm{CO}_{2} \text { (gas) }+(n+1) \mathrm{H}_{2} \mathrm{O} \text { (liquid), }
\end{aligned}
$$

at a temperature of $25 \mathrm{C}$ and a constant pressure of 1 atmosphere, in $\mathrm{k}-\mathrm{cal}_{15}$ per mole: normal butanol, $638.93 \pm 0.38$; normal pentanol, $794.89 \pm 0.48$; normal hexanol, $951.05 \pm 0.57$; normal heptanol, $1,107.51 \pm 0.66$; normal octanol, $1,263.96 \pm 0.76$; normal nonanol, $1,419.79 \pm 0.85$; normal decanol, $1,575.60 \pm 0.95$.

\section{SELECTED VALUES FOR THE HEATS OF COMBUSTION OF THE ALCOHOLS IN THE LIQUID STATE}

The various values given in the foregoing section are plotted in figure 2 , in terms of the function $(Q c-12.00) / n$, where $Q c$ is the heat of reaction (1) in k-cal ${ }_{15}$ per mole, $n$ is the number of carbon atoms in the molecule, and the constant 12.00 , chosen arbitrarily, is used in 
order to obtain a compact plot of the values. From the curve in this plot, the values given in table 2 have been selected as the "best" values for the heat evolved in reaction (1) at a temperature of $25 \mathrm{C}$ and a constant pressure of 1 atmosphere.

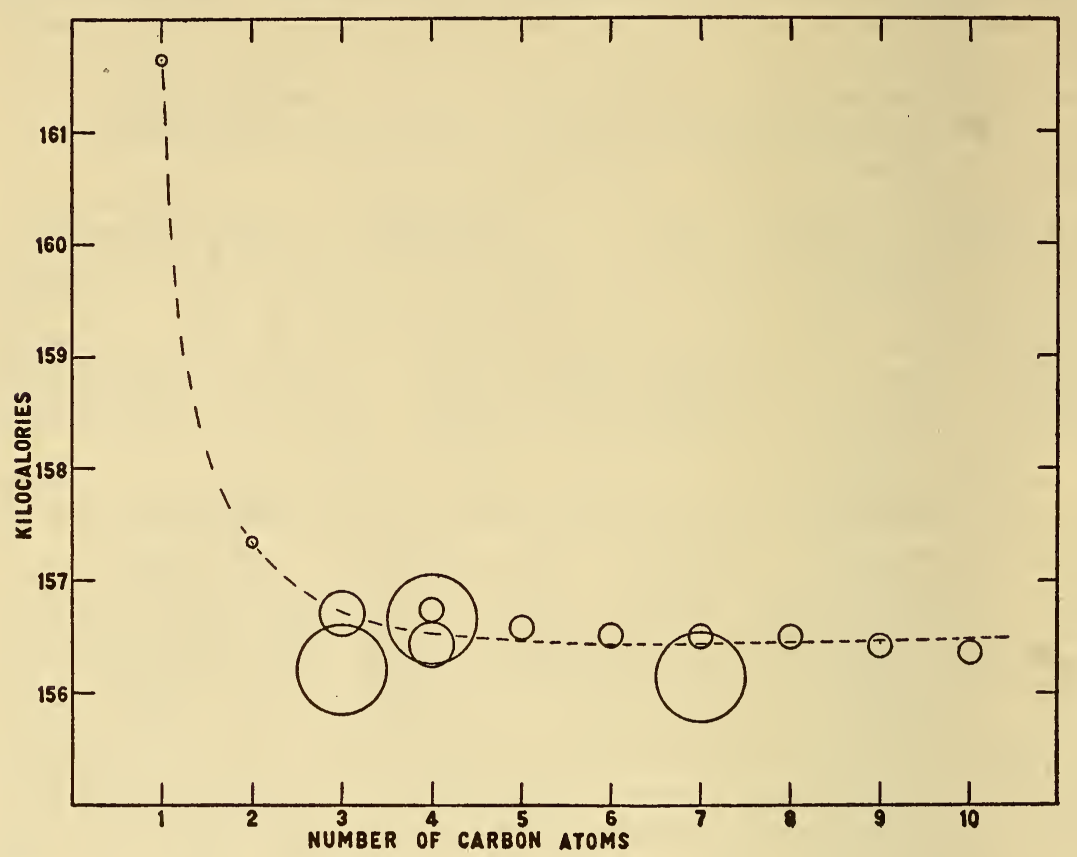

FIGURE 2.-Plot of the various data on the heats of combustion of the normal aliphatic alcohols in the liquid state.

The scale of ordinates gives the function $(Q c-12.00) / n$, in $\mathrm{k}$-cal 15 per carbon atom, where $Q c$ is the heat of combustion of the liquid, in $\mathrm{k}$-cal 15 per mole, at 25 centigrade and a constant pressure of 1 atmosphere. The scale of abscissas gives $n$, the number of carbon atoms in the molecule. The circles are drawn with radii equal to the estimated uncertainties in the various values, the sources of which are given in the text.

TABLE 2.-Selected "best" values for the heats of combustion of the normal aliphatic alcohols in the liquid state at a temperature of $25 C$ and a constant pressure of 1 atmosphere

$$
\left[\mathrm{C}_{n} \mathrm{H}_{2 n+1} \mathrm{OH} \text { (liquid) }+\frac{3 n}{2} \mathrm{O}_{2} \text { (gas) }=n \mathrm{CO}_{2} \text { (gas) }+(n+1) \mathrm{H}_{2} \mathrm{O}\right. \text { (liquid] }
$$

\begin{tabular}{|c|c|c|c|}
\hline Normal $\mathrm{C}_{n} \mathrm{H}_{2 n+1} \mathrm{OH}$ (liquid) & $\begin{array}{c}\text { Heat of com- } \\
\text { bustion at } 25 \\
\text { centigrade and } \\
\text { constant pres- } \\
\text { sure }\end{array}$ & Normal $\mathrm{C}_{n} \mathrm{H}_{2 n+1} \mathrm{OH}$ (liquid) & $\begin{array}{l}\text { Heat of com- } \\
\text { bustion at } 25 \\
\text { centigrade and } \\
\text { constant pres- } \\
\text { sure }\end{array}$ \\
\hline 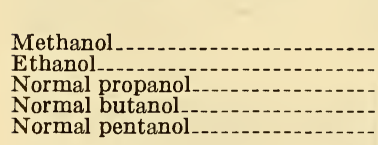 & \begin{tabular}{|r|}
$k-c a l_{15}$ per mole \\
$173.64 \pm 0.05$ \\
$326.66 \pm 0.10$ \\
$482.15 \pm 0.24$ \\
$638.10+0.32$ \\
$794.30 \pm 0.40$
\end{tabular} & $\begin{array}{l}\text { Normal hexanol-.-- } \\
\text { Normal heptanol--: } \\
\text { Normal octanol } \\
\text { Normal nonano---: } \\
\text { Normal decanol---- }\end{array}$ & $\begin{array}{r}k-c a l_{15} \text { per mole } \\
950.55 \pm 0.48 \\
1,107.05 \pm 0.56 \\
1,263.60 \pm 0.64 \\
1,420.20 \pm 0.72 \\
1,576.90 \pm 0.80\end{array}$ \\
\hline
\end{tabular}




\section{SELECTED VALUES FOR THE HEATS OF COMBUSTION OF THE ALCOHOLS IN THE GASEOUS STATE}

Combination of the selected "best" values for the heats of combustion of the normal aliphatic alcohols in the liquid state with the selected "best" values for the heats of vaporization yields selected "best" values for the heats of combustion of the alcohols in the gaseous state according to the reaction,

$$
\mathrm{C}_{n} \mathrm{H}_{2 n+1} \mathrm{OH} \text { (gas) }+\frac{3 n}{2} \mathrm{O}_{2} \text { (gas) }=n \mathrm{CO}_{2} \text { (gas) }+(n+1) \mathrm{H}_{2} \mathrm{O} \text { (liquid), }
$$

at a temperature of $25 \mathrm{C}$ and a constant total pressure of 1 atmosphere. These values are given in table 3 and are plotted in figure 3.

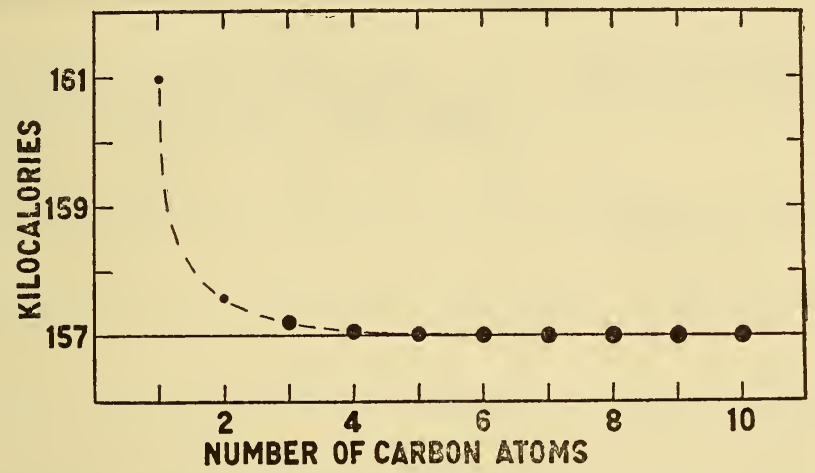

FIgURE 3.-Plot of the selected "best" values for the heats of combustion of the normal aliphatic alcohols in the gaseous state.

The scale of ordinates gives the function $(Q c-21.60) / n$, in $\mathrm{k}$-cal 15 per carbon atom, where $Q c$ is the heat of combustion of the gas, in $\mathrm{k}-\mathrm{cal}_{15}$ per mole, at 25 centigrade and a constant total pressure of 1 atmosphere. The scale of abscissas gives $n$, the number of carbon atoms in the molecule. The circles are drawn with radii equal to the estimated uncertainties.

TABLE 3.-Selected "best" values for the heats of combustion of the normal aliphatic alcohols in the gaseous state at a temperature of $25 \mathrm{C}$ and a constant total pressure of 1 atmosphere

$$
\left[\mathrm{C}_{n} \mathrm{H}_{2 n+1} \mathrm{OH} \text { (gas) }+\frac{3 n}{2} \mathrm{O}_{2} \text { (gas) }=n \mathrm{CO}_{2} \text { (gas) }+(n+1) \mathrm{H}_{2} \mathrm{O} \text { (liquid) }\right]
$$

\begin{tabular}{|c|c|c|c|}
\hline Normal $\mathrm{C}_{n} \mathrm{H}_{2 n+1} \mathrm{OH}$ (gas) & $\begin{array}{l}\text { Heat of combustion } \\
\text { at } 25 \text { centigrade and } \\
\text { constant pressure }\end{array}$ & Normal $\mathrm{C}_{n} \mathrm{H}_{2 n+1} \mathrm{OH}$ (gas) & $\begin{array}{l}\text { Heat of combustion } \\
\text { at } 25 \text { centigrade and } \\
\text { constant pressure }\end{array}$ \\
\hline $\begin{array}{l}\text { Methanol } \\
\text { Ethanol } \\
\text { Normal propanol- } \\
\text { Normal butanol } \\
\text { Normal pentanol- } \\
\text { Normal hexanol- }\end{array}$ & $\begin{array}{l}k \text {-cal } 15 \text { per mole } \\
182.58 \pm 0.05 \\
336.78 \pm 0.10 \\
493.20 \pm 0.28 \\
649.90 \pm 0.40 \\
806.75 \pm 0.53 \\
963.60 \pm 0.66\end{array}$ & $\begin{array}{l}\text { Normal heptanol } \\
\text { Normal octanol } \\
\text { Normal nonanol-al } \\
\text { Normal decanol } \\
\text { Normal } \mathrm{C}_{n} H_{2 n+1} \mathrm{OH}, n>5 \\
\end{array}$ & $\begin{array}{r}k \text {-cal }{ }_{15} \text { per mole } \\
1,120.60 \pm 0.78 \\
1,277.60 \pm 0.94 \\
1,434.60 \pm 1.11 \\
1,591.60 \pm 1.28 \\
21.60+n(157.00 \pm 0.12)\end{array}$ \\
\hline
\end{tabular}

The values of the heats of combustion of the gaseous normal aliphatic alcohols are a linear function of $n$ above, but not below, $n$ equal to about 6 . The deviations from linearity are in the direction of greater values of the heats of combustion, and are, in kilocalories per mole: methanol, $3.98 \pm 0.05$; ethanol, $1.18 \pm 0.10$; normal propanol, $0.60 \pm 0.28$; normal butanol, $0.30 \pm 0.40$; normal pentanol, $0.15 \pm 0.53$. 


\section{CHANGE IN HEAT CONTENT, AT 25 CENTIGRADE} AND AT ZERO KELVIN, FOR THE REACTION OF ADDING $1 / 2 \mathrm{O}_{2}$ TO A NORMAL PARAFFIN HYDROCARBON TO FORM THE CORRESPONDING NORMAL ALIPHATIC ALCOHOL

The difference in the heats of combustion of the gaseous normal paraffin hydrocarbons and their analogous gaseous normal aliphatic alcohols yields the change in heat content for the process of adding $1 / 2 \mathrm{O}_{2}$ (gas) to normal $\mathrm{C}_{n} \mathrm{H}_{2 n+2}$ (gas) to form normal $\mathrm{C}_{n} \mathrm{H}_{2 n+1} \mathrm{OH}$ (gas):

$$
\mathrm{C}_{n} \mathrm{H}_{2 n+2} \text { (gas) }+1 / 2 \mathrm{O}_{2} \text { (gas) }=\mathrm{C}_{n} \mathrm{H}_{2 n+1} \mathrm{OH} \text { (gas) }
$$

Using for the heats of combustion of the gaseous normal paraffin hydrocarbons the values given by the writer in a previous paper (1),

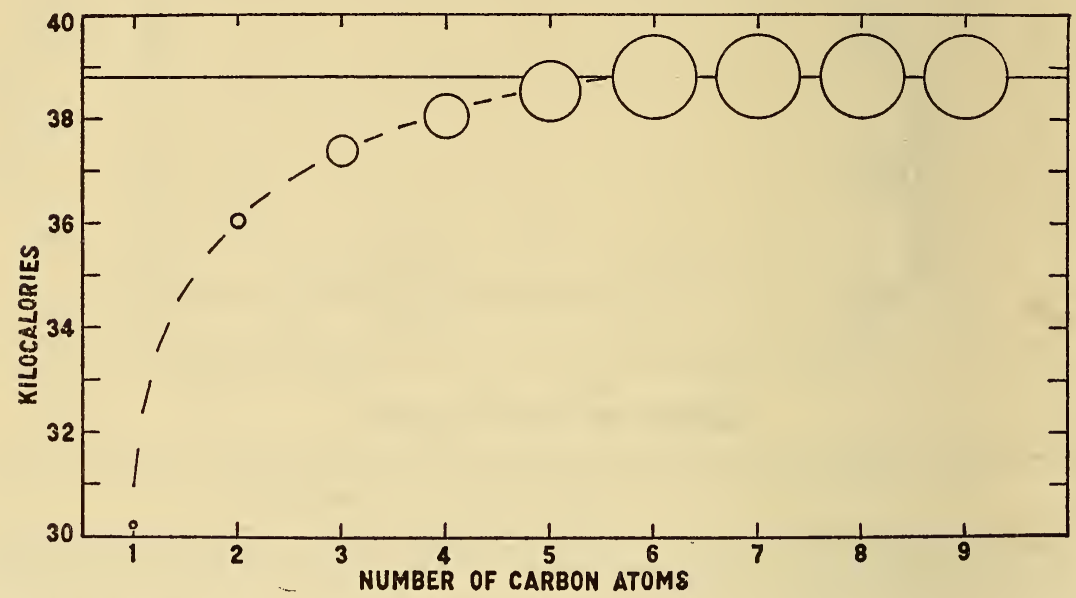

FIGURE 4.-Plot of the values for the heat of the reaction of adding $1_{2} \mathrm{O}_{2}$ to a normal paraffin hydrocarbon to form the corresponding normal aliphatic alcohol.

The scale of ordinates gives the heat evolved in the reaction, normal $\mathrm{C}_{n} \mathrm{H}_{2 n+2}$ (gas) $+1 / 2 \mathrm{O}_{2}$ (gas) $=$ normal $\mathrm{C}_{n} \mathrm{H}_{2 n+1} \mathrm{OH}$ (gas), at 25 centigrade and a constant total pressure of 1 atmosphere, in $\mathrm{k}$-cal ${ }_{15}$ per mole. The scale of abscissas gives the number of carbon atoms in the molecule. The circles are drawn with radii equal to the estimated uncertainties.

and for the heats of combustion of the normal aliphatic alcohols the values given in table 3 of this paper, the writer obtains the values given in table 4 for the change in heat content for reaction 3 at.a temperature of $25 \mathrm{C}$ and a constant total pressure of 1 atmosphere. These values are plotted in figure 4.

TABLE 4.-The change in heat content, at 25 centigrade and at zero Kelvin, for the reaction of adding $1 \frac{1}{2} \mathrm{O}_{2}$ to a normal paraffin hydrocarbon to form the corresponding normal aliphatic alcohol

$\left[\mathrm{C}_{n} \mathrm{H}_{2 n+2}\right.$ (gas) $+1 / 2 \mathrm{O}_{2}$ (gas) $=\mathrm{C}_{n} \mathrm{H}_{2 n+1} \mathrm{OH}$ (gas) $]$

\begin{tabular}{|c|c|c|}
\hline$n$ & $\Delta H^{\circ}{ }_{298.1}$ & $\Delta H^{\circ}{ }_{0}$ \\
\hline & $k$-cal ${ }_{16}$ per mole & k-cal 16 per mole \\
1 & $-30.21 \pm 0.08$ & $-29.98 \pm 0.13$ \\
2 & $-36.03 \pm 0.15$ & $-35.80 \pm 0.18$ \\
3 & $-37.37 \pm 0.30$ & $-37.14 \pm 0.32$ \\
4 & $-38.04 \pm 0.43$ & $-37.81 \pm 0.45$ \\
5 & $-38.52 \pm 0.57$ & $-38.29 \pm 0.59$ \\
6 & $-38.80 \pm 0.82$ & $-38.57 \pm 0.84$ \\
$n>5$ & $-38.80 \pm 0.82$ & $-38.57 \pm 0.84$ \\
\hline
\end{tabular}


In order to compute the change in heat content for reaction 3 at zero Kelvin, there are required values of the quantity $H^{\circ}{ }_{298.1}-H^{\circ}{ }_{0}$ for normal $\mathrm{C}_{n} \mathrm{H}_{2 n+2}$ (gas), $\mathrm{O}_{2}$ (gas), and normal $\mathrm{C}_{n} \mathrm{H}_{2 n+1} \mathrm{OH}$ (gas). Values for the first two substances are given in the previous paper (1). There have not been published any calculations of this quantity for the gaseous normal aliphatic alcohols; but the writer estimates, from the published meager data on the difference in the heat capacities of methane and methanol and of ethane and ethanol, that the value of $H^{\circ}{ }_{298.1}-H^{\circ}{ }_{0}$ for normal $\mathrm{C}_{n} \mathrm{H}_{2 n+1} \mathrm{OH}$ (gas) is greater than that for the corresponding normal paraffin hydrocarbon by about $0.80 \pm 0.10$ $\mathrm{k}$-cal per mole.

Hence for reaction 3 ,

$\Delta H^{\circ}{ }_{0}=\Delta H^{\circ}{ }_{288.1}-(0.70 \pm 0.10) \mathrm{k}-\mathrm{cal}_{15}$ per mole

The values so obtained are given in table 4 .

\section{HEATS OF FORMATION OF THE NORMAL ALI- PHATIC ALCOHOLS FROM SOLID CARBON AND GASE- OUS HYDROGEN AND OXYGEN}

Combination of the values given in tables 1 and 4 of this paper with those given in table 2 of the previous paper (1) yields for the reactions, and

$$
\mathrm{C}(\beta \text { graphite })+(n+1) \mathrm{H}_{2} \text { (gas) }+1 / 2 \mathrm{O}_{2} \text { (gas) }=\mathrm{C}_{n} \mathrm{H}_{2 n+1} \mathrm{OH} \text { (gas) }
$$

$\mathrm{C}$ (diamond) $+(n+1) \mathrm{H}_{2}$ (gas) $+1 / 2 \mathrm{O}_{2}$ (gas) $=\mathrm{C}_{n} \mathrm{H}_{2 n+1} \mathrm{OH}$ (gas),

at temperatures of $25 \mathrm{C}$ and zero Kelvin and a constant total pressure of 1 atmosphere, the values given in table 5 . There are also included in table 5 values for the analogous formation of the normal aliphatic alcohols in the liquid state at a temperature of $25 \mathrm{C}$. 


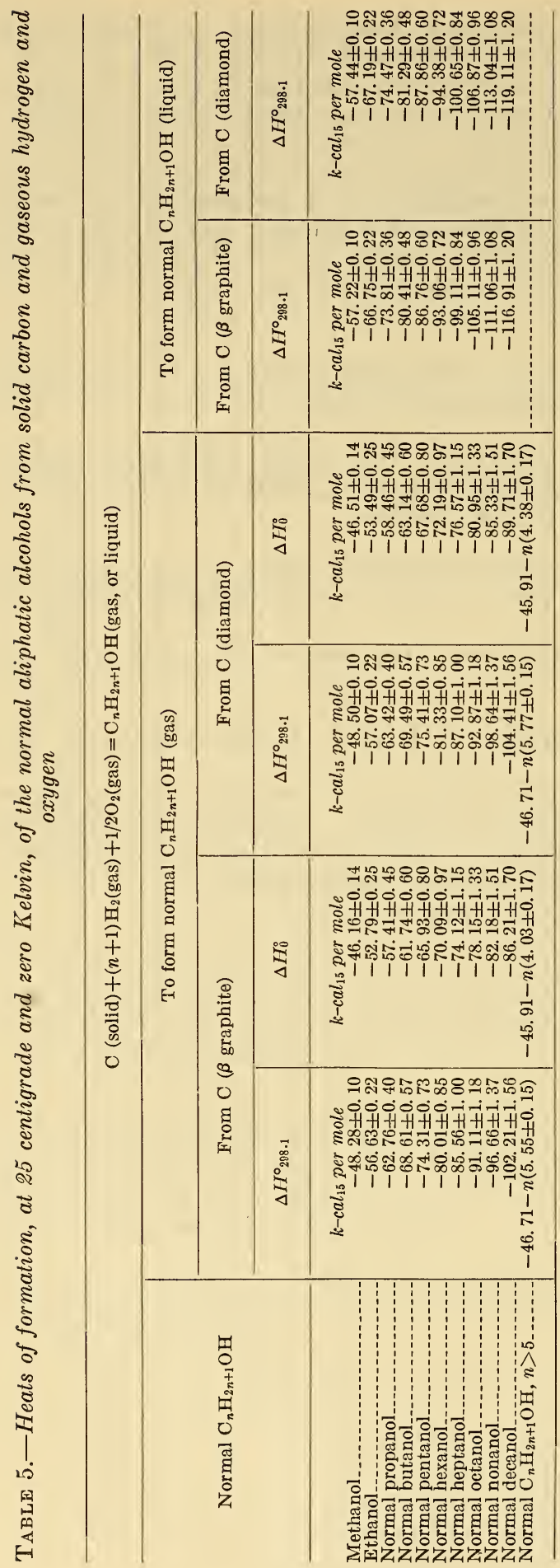


IX. ENERGY OF DISSOCIATION OF NORMAL $\mathrm{C}_{n} \mathrm{H}_{2 n+1} \mathrm{OH}$ INTO GASEOUS ATOMS, AND THE ENERGIES OF THE ATOMIC LINKAGES

The energy absorbed at the absolute zero in the reaction of dissociating the gaseous molecule $\mathrm{C}_{n} \mathrm{H}_{2 n+1} \mathrm{OH}$ (normal aliphatic alcohol), into its constituent gaseous atoms, each in the normal state,

$$
\mathrm{C}_{n} \mathrm{H}_{2 n+1} \mathrm{OH} \text { (gas) }=n \mathrm{C} \text { (gas) }+(2 n+2) \mathrm{H} \text { (gas) }+\mathrm{O} \text { (gas), }
$$

is given by the expression,

$(D a)_{\circ}^{\circ}=-Q c_{298.1}+n(132.880 \pm 0.032)+(65.256 \pm 0.010)+n D_{\mathrm{CO}}+$

$$
(n+1) D_{\mathrm{H}_{2}}-\frac{n-1}{2} D_{\mathrm{o}_{2}}+\left(H^{\circ}{ }_{298.1}-H_{\circ}^{\circ}\right)[\text { alcohol], }
$$

where $Q c_{298.1}$ is the heat evolved in the combustion of the normal aliphatic alcohol according to reaction (2), $D_{\mathrm{co}}, D_{\mathrm{H}_{2}}$, and $D_{\mathrm{o}_{2}}$ are the

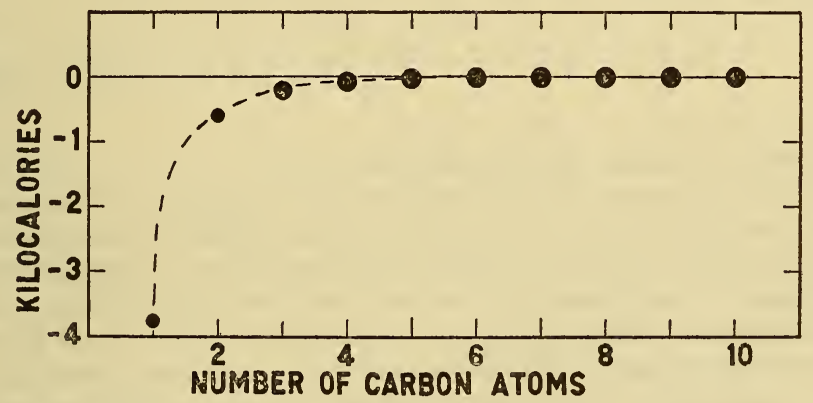

FIGURE 5.-Plot of the deviations from linearity in the relation between the number of carbon atoms in the normal aliphatic molecule and its energy of dissociation into atoms.

The scale of ordinates gives $\Delta$, the deviation from linearity in the relation between $n$ and the energy of dissociation at zero Kelvin, according to the reaction, $\mathrm{C}_{n} \mathrm{H}_{2 n+1} \mathrm{OH}(\mathrm{gas})=n \mathrm{C}$ (gas) $+(2 n+2) \mathrm{H}$ (gas) $+\mathrm{O}$ (gas), in kilocalories per carbon atom. The scale of abscissas gives $n$, the number of carbon atoms in the molecule. The circles are drawn with radii equal to the estimated uncertainties.

energies absorbed at the absolute zero in the reaction of dissociating the molecules $\mathrm{CO}, \mathrm{H}_{2}$ and $\mathrm{O}_{2}$, in the normal state, into their constituent atoms, each in the normal state, and the last term is the heat content of the gaseous normal aliphatic alcohol at 298.1 Kelvin minus its heat content at zero Kelvin. For the values of $H_{298.1}^{\circ}-H_{\circ}^{\circ}$ for the gaseous normal aliphatic alcohols, the writer takes the following values (see preceding section): Methanol, $3.20 \pm 0.10 ; n>1,(2.25 \pm$ $0.10)+0.75 n(1 \pm 0.01 n), \mathrm{k}$-cal per mole.

By means of equation 8 and the values given here, the writer has computed the values for $\Delta$, the deviation from linearity in the relation between $(D a)^{\circ}$ and $n$, which are given in table 6 and plotted in figure 5 . 
TABLE 6.-Deviations from linearity with $n$ in the energy of dissociation, at the absolute zero, of the normal aliphatic alcohols into their constituent atoms

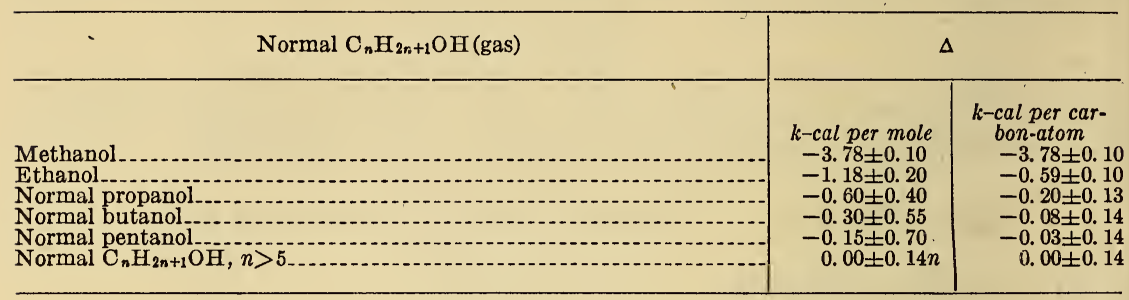

For any of the normal aliphatic alcohols, the energy of reaction,

$$
\mathrm{C}_{n} \mathrm{H}_{2 n+1} \mathrm{OH}(\text { gas })=n \mathrm{C}(\text { gas })+(2 n+2) \mathrm{H} \text { (gas) }+\mathrm{O} \text { (gas), }
$$

when all the substances are in their normal states at the absolute zero of temperature, is given by the equation

$$
\begin{aligned}
(D a)_{\circ}^{\circ}=(45.91 \pm 0.10)-n(23.37 \pm & 0.14)+n D_{\mathrm{co}}+(n+1) D_{\mathrm{H}_{2}}- \\
& \frac{n-1}{2} D_{\mathrm{o}_{2}}+\Delta \mathrm{k}-\mathrm{cal}_{15} \text { per mole, }
\end{aligned}
$$

where $\Delta$ has the values given in table 6 .

Within the accuracy of these values, the energy of dissociation of the gaseous normal aliphatic alcohol, $\mathrm{C}_{n} \mathrm{H}_{2 n+1} \mathrm{OH}$, into its constituent atoms is a linear function of $n$ above, but not below, $n$ equal to about 6 . The deviations from linearity are in the direction of lesser stability of the molecule and reach a maximum value of $3.78 \pm 0.10$ kilocalories per mole for methanol. These deviations are of opposite sign from, and have values about $2 / 3$ of, those found for the corresponding normal paraffin hydrocarbons.

In a manner similar to that used by the writer in the case of the normal paraffin hydrocarbons (1), the above deviations can be explained by assuming different kinds of $\mathrm{C}-\mathrm{C}, \mathrm{C}-\mathrm{H}$, and $\mathrm{C}-\mathrm{O}$ linkages in the normal aliphatic alcohols. For example, one can distinguish two kinds of $\mathrm{C}-\mathrm{H}$ linkages and two kinds of $\mathrm{C}-\mathrm{O}$ linkages in the molecule

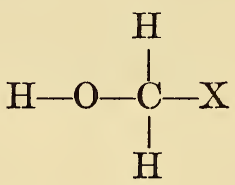

$a_{\sharp}$ is the $\mathrm{C}-\mathrm{H}$ linkage when $\mathrm{X}=\mathrm{H}$,

$a_{5}$ is the $\mathrm{C}-\mathrm{H}$ linkage when $\mathrm{X}=\mathrm{R}$ (a normal alkyl radical),

$d_{1}$ is the $\mathrm{C}-\mathrm{O}$ linkage when $\mathrm{X}=\mathrm{H}$,

$d_{2}$ is the $\mathrm{C}-\mathrm{O}$ linkage when $\mathrm{X}=\mathrm{R}$, and

$c_{1}$ is the $\mathrm{O}-\mathrm{H}$ linkage. 
Similarly, one can distinguish two kinds of $\mathrm{C}-\mathrm{C}$ linkages in the molecule<smiles>[X]CCO</smiles>

$b_{10}$ is the $\mathrm{C}-\mathrm{C}$ linkage when $\mathrm{X}=\mathrm{H}$ and

$b_{11}$ is the $\mathrm{C}-\mathrm{C}$ linkage when $\mathrm{X}=\mathrm{R}$.

On this basis the energies of the atomic linkages in the normal aliphatic alcohols can be represented as follows:

$$
\begin{array}{ll}
\text { Methanol_... } & c_{1}+d_{1}+3 a_{4} \\
\text { Ethanol } & c_{1}+d_{2}+2 a_{5}+3 a_{1}+b_{10} \\
\text { Normal } \mathrm{C}_{n} \mathrm{H}_{2 n+1} \mathrm{OH},(n>2) & \begin{array}{c}
c_{1}+d_{2}+2 a_{5}+3 a_{1}+b_{10} \\
\\
\end{array} \quad+b_{11}+2(n-2) a_{2}+(n-3) b_{2} .
\end{array}
$$

The successive differences become constant and equal to $2 a_{2}+b_{2}$ above $n=3$. This approximates what the experimental data indicate, but (as previously pointed out in the case of the normal paraffin hydrocarbons) in a more exact sense one would need to distinguish between various normal alkyl radicals designated by $R$ in the above notation.

Whereas, for the series of normal paraffin hydrocarbons the positive deviations from linearity in going from hexane to methane could be attributed in large part to the fact that the strengths of the $\mathrm{C}-\mathrm{H}$ linkages are in the increasing order $a_{2}, a_{1}, a_{0}$; for the series of normal aliphatic alcohols the negative deviations from linearity in going from hexanol to methanol can be explained in large part by assuming that the strengths of the C--O linkages are in the decreasing order $d_{2}, d_{1}$.

Within the accuracy of the present values, each atom in the molecule may be said to have a sphere of influence, with regard to energy, that includes the atoms twice removed from it.

Any assignment of values for the energies of the various linkages in the normal aliphatic molecule, $\mathrm{C}_{n} \mathrm{H}_{2 n+1} \mathrm{OH}$, must satisfy the following relation:

$$
\Sigma m_{i} l_{i}=(D a)_{0}^{0}+n E_{c}
$$

Here $l_{i}$ is the value assigned to represent the energy of each atomic linkage of the kind $i$, the number of which is $m_{i} ; E_{c}$ is the energy of excitation of the carbon atom to the excited tetravalent ${ }^{5} \mathrm{~S}$ state; $n$ is the number of carbon atoms in the molecule; and $(D a)^{0}{ }_{0}$ is given by equation 9 .

\section{REFERENCES}

1. Rossini, BS J.Research 13,21(1934).

2. Rossini, BS J.Research 12,735(1934).

3. Baxter, Curie, Hönigschmid, Le Beau and Meyer, J. Am. Chem. Soc. 56, $753(1934)$.

4. Washburn, BS J.Research 10,525(1933).

5. International Critical Tables, 5,136-139(1929), McGraw Hill Book Co., New York.

6. Bartoszewicz, Roczniki Chem. 11,90(1931); Bull. intern. acad. Polonaise A, 1931,348(1931). 
7. Fiock, Ginnings, and Holton, BS J.Research 6,881(1931).

8. Rossini, BS J.Research 8,119(1932).

9. Louguinine, Ann. chim. phys. 25,140(1882).

10. Zubow, J.Russ. Phys.-Chem. Soc. 30,926(1898); 33,708(1901); 35,815 (1903).

11. Richards and Davis, J.Am. Chem. Soc. 42,1599(1920).

12. Verkade and Coops, Rec. trav. chim. 46,903(1927).

13. Swietoslawski, J.Am. Chem. Soc. 42,1092(1920).

14. Jessup, J.Research N.B.S., forthcoming number.

Washington, June 13, 1934. 